\title{
FATTY MUSCLE INFILTRATION IN CUFF TEAR: PRE AND POST OPERATIVE EVALUATION BY MRI
}

\author{
alberto Naoki Miyazaki ${ }^{1}$, Pedro Doneux Santos ${ }^{1}$, Luciana Andrade da Silva ${ }^{1}$, Guilherme do Val Sella ${ }^{1}$, \\ Eduardo RéGIS de Alencar Bona Miranda ${ }^{1}$, Rodrigo ZampierI ${ }^{1}$
}

\section{ABSTRACT}

Objective: To evaluate the fatty infiltration and atrophy of the supraespinatus in the pre- and postoperative of a rotator cuff lesion (RCL), by MRI. Methods: Ten patients with full-thickness rotator cuff tears who had undergone surgical arthroscopic rotator cuff repair between September and December 2011 were included. This is a prospective study, with analysis and comparison of fatty infiltration and atrophy of the supraespinatus. The occupation ratio was measured using the magic selection tool in Adobe Photoshop CS3 ${ }^{\circledR}$ on T1 oblique sagittal Y-view MRI. Through Photoshop, the proportion occupied by the muscle belly regarding its fossae was calculated. Results: There was a statistically significant increase in the muscle ratio $(p=0.013)$ comparing images pre and postoperative, analyzed by the Wilcoxon T test. Conclusion: The proportion of the supraspinal muscle above the pit increases in the immediate postoperative period, probably due to the traction exerted on the tendon at the time of repair.

\section{Level of Evidence II, Cohort Study.}

Keywords: Rotator cuff/pathology. Muscular atrophy. Magnetic resonance imaging.

Citation: Miyazaki AN, Santos PD, Silva LA, Val Sella G, Miranda ERA, Zampieri R. Fatty muscle infiltration in cuff tear: pre and post operative evaluation by MRI. Acta Ortop Bras. [online]. 2015;23(5):251-4. Available from URL: http://www.scielo.br/aob.

\section{INTRODUCTION}

Rotator cuff injury $(\mathrm{RCl})$ is among the most common diseases affecting the shoulder, with an incidence of up to $54 \%$ of individuals over 60 years old, ${ }^{1}$ and its chronicity may be accompanied by tendon retraction and fatty infiltration, ${ }^{2}$ which is progressive and irreversible..$^{3-5}$

Initially, Goutallier et al. ${ }^{6}$ described fatty infiltration of the rotator cuff muscles (RC) after tendon rupture and created a classification system with five stages using computed tomography (CT) of infra and subscapularis spinal muscles, which became a reference in determining fatty infiltration. The increasing use of magnetic resonance imaging (MRI) for diagnosis of shoulder diseases and even for assessment of fatty infiltration, cause the development of several works with the purpose of using MRI to such purpose. ${ }^{7-9}$ In 2011 Tae et al. ${ }^{10}$ found a significant correlation between $\mathrm{CT}$ and MR images using a quick selection tool in Photoshop $\mathrm{CS}^{\circledR}$ to assess fatty infiltration and muscle atrophy of the rotator cuff.

Some authors, such as Fuchs et al.., ${ }^{11}$ Jost et al. ${ }^{12}$ and Liem et al..$^{5}$ expanded the concept of fatty infiltration, demonstrating that the degree of infiltration does not decrease after surgical repair, and even has a tendency to increase depending on the preoperative state of the muscle, ${ }^{13}$ even being considered as a negative prognosis.

The objective of this study was to evaluate fatty infiltration and atrophy of the supraspinatus in the preoperative period and immediately after repair in order to verify whether the traction exerted on the tendon to reinsert it alters the muscle in his fossa on immediate postoperative MR image.

\section{CASES AND METHODS}

From September 2011 to December 2011, ten patients (four men and six women) followed at the Shoulder and Elbow Group, Department of Orthopedics and Traumatology, Faculdade de Ciências Médicas da Santa Casa de São Paulo - "PaviIhão Fernandinho Simonsen" SP, Brazil, diagnosed with full RCI underwent repair of the injury and MRI study of the patient's shoulder, pre- and postoperatively. A prospective study was performed with analysis and comparison of infiltration and supraspinatus muscle atrophy using MR images taken before and after surgery.

As inclusion criteria, patients with complete $\mathrm{RCl}$ and fatty infiltration,

All the authors declare that there is no potential conflict of interest referring to this article.

\footnotetext{
1. Faculdade de Ciências Médicas da Santa Casa de São Paulo, "Pavilhão Fernandinho Simonsen”, Department of Orthopedics and Traumatology, Shoulder and Elbow Group, São Paulo, SP, Brazil.

Work developed at Faculdade de Ciências Médicas da Santa Casa de São Paulo, "Pavilhão Fernandinho Simonsen", Department of Orthopedics and Traumatology, Shoulder and Elbow Group, São Paulo, SP, Brazil.

Correspondence: Santa Casa de Misericórdia de São Paulo, Departamento de Ortopedia e Traumatologia, "Pavilhão Fernandinho Simonsen". Rua Dr. Cesário Mota Júnior, 112, Vila Buarque.01220-020 São Paulo, SP Brazil.ombro@ombro.med.br
} 
ranked according to Goutallier et al., ${ }^{6}$ stage I or above and supraspinatus muscle atrophy in the preoperative MR images, and those who at surgery had a proper tendon reintegration. Patients with partial $\mathrm{RCl}$, isolated lesions of the subscapularis, previous surgery on the shoulder, signs or symptoms of infection were excluded from the study.

The ten patients participating in the study (Table 1) were on average 59.4 years old (range, 54-68 years old), in eight cases the dominant side was the injured shoulder. The time presenting symptoms ranged from three to 120 months, averaging 60 months. Two patients reported well-defined trauma episode, which led to the appearance or sudden worsening of symptoms. To assess the degree of mobility of the shoulder joint, we used the AAOS ${ }^{14}$ (American Academy of Orthopedic Surgeons) method, which takes into account the extent of medial rotation, lateral rotation and elevation movements. The observed preoperative values were, om average, $118^{\circ}$ elevation (range, $90^{\circ}-150^{\circ}$ ) $45.5^{\circ}$ lateral rotation (range $20^{\circ}-70^{\circ}$ ) and medial rotation at T11 level (range, T8-L2).

Functional assessment of patients was performed using method of UCLA (University of California at Los Angeles), ${ }^{15}$ obtaining an average score of 16.6 (range 10-20) before surgery.

All injuries were considered extensive, according to Gerber et al., ${ }^{16}$ since in all of them the supraspinatus and infraspinatus were damaged, and in no case the tendon of the subscapularis and teres minor were injured. According to the classification by Cofield et al., ${ }^{17} 40 \%$ of patients had injuries considered as large $(3-5 \mathrm{~cm})$ and $60 \%$ had injuries considered as medium $(1-3 \mathrm{~cm})$. Regarding muscle fatty infiltration the classification described by Goutallier et al. ${ }^{6}$ was adopted. This system, which takes into account the amount of fat within the muscle, is divided into five evolutionary stages. Zero stage presents with muscle without fat; Stage I contains some fatty streaks within the muscle; stage II, there is already an important fatty infiltration, but still a higher proportion of muscle; stage III, fat and muscle are proportionately equal; and in stage IV, there is more fat than muscle. In the study sample, five patients were considered as stage I according to Goutallier et al. ${ }^{6}$ for supraspinatus muscle and five patients had stage III; according to the infraspinatus, seven were considered stage I, two were stage II and one at stage III. The fatty infiltration remained unchanged in the postoperative regarding this classification. Image interpretation was made by an Orthopedics and Traumatology physician specialized in shoulder and elbow surgery.

All surgeries were performed at Pavilhão Fernadinho Simonsen, two surgeries were open procedures and eight by the arthroscopic route. In seven of them an acromioplasty (ACR) was performed along with repair of the injury. In one patient acromioplasty, tenotomy of the long head of the biceps (TLHB) and repair of the injury were performed. In one patient repair of the injury and TLBH was made and, in one patient it was chosen to repair the injury without other procedures, due to the bad quality of the tendons.

MRI examinations were performed on a high-field 1.5 Tesla equipment (Achieva, Philips Medical Systems, Netherlands B.V. ${ }^{\circledR}$ ). Sagittal and oblique coronal images were obtained referring to the glenoid cavity, T1 and T2 weighted, as well as images in the axial plane weighted in proton density. The exams were performed with a maximum interval of one month between the pre- and postoperative period.

The MR images were analyzed in the reports program of the Department of Radiology and Diagnostic Imaging (Impax Results Viewer software 6.4.0.4513 - Agfa Healthcare ${ }^{\circledR}$ ).

Aiming to evaluate the muscular atrophy and fatty infiltration, the proportion that the muscle belly of the supraspinatus occupied regarding its fossa, in both pre and post-operative examinations. The weighted oblique sagittal T1 sequence, in which fat is observed with high signal and the muscle with intermediate signal, is the most appropriate for defining the studied structures. The chosen cutoff was the most lateral, on which the spine of the scapula shows a continuation with the body forming a "Y" shape. (Figure 1) To calculate the total area of the supraspinatus fossa its limits were set as the internal bony margins of the spine and body of the scapula superiorly formed by the bottom edge of the

Table 1. Surgical cases of the study.

\begin{tabular}{|c|c|c|c|c|c|c|c|c|c|c|c|c|c|c|c|c|c|c|c|c|c|c|}
\hline \multirow{3}{*}{$\mathbf{N}$} & \multirow{3}{*}{ Gender } & \multirow{3}{*}{$\begin{array}{c}\text { Age } \\
\text { (years } \\
\text { old) }\end{array}$} & \multirow{3}{*}{ Dom } & \multirow{3}{*}{$\mid \begin{array}{c}\text { TS } \\
\text { (months) }\end{array}$} & \multirow{3}{*}{\begin{tabular}{|l|} 
TH \\
\\
\end{tabular}} & \multicolumn{12}{|c|}{ PREOPERATIVE } & \multicolumn{5}{|c|}{ POSTOPERATIVE } \\
\hline & & & & & & \multirow{2}{*}{\begin{tabular}{|l|}
$\begin{array}{l}\text { MOVEMENT } \\
\text { (Elev/LR/MR) }\end{array}$ \\
\end{tabular}} & \multicolumn{5}{|c|}{ UCLA } & \multirow[t]{2}{*}{$\mathrm{TL}$} & \multirow{2}{*}{$\begin{array}{l}\text { Injured } \\
\text { Tendons }\end{array}$} & \multirow{2}{*}{$\begin{array}{c}G \\
\text { (SS) }\end{array}$} & \multirow{2}{*}{$\begin{array}{c}G \\
\text { (IS) }\end{array}$} & \multirow{2}{*}{$\begin{array}{c}\text { AOM } \\
\text { (pixels) }\end{array}$} & \multirow{2}{*}{ PAOM } & \multirow{2}{*}{$\begin{array}{c}\text { Surgical } \\
\text { technique }\end{array}$} & \multirow{2}{*}{$\begin{array}{c}\text { MOA } \\
\text { (pixels) }\end{array}$} & \multirow[t]{2}{*}{ PMOA } & \multirow{2}{*}{$\begin{array}{c}G \\
\text { (SS) }\end{array}$} & \multirow{2}{*}{$\begin{array}{c}G \\
\text { (IS) }\end{array}$} \\
\hline & & & & & & & $\mathrm{P}$ & AAF & FAFS & $\mathbf{S}$ & $\mathbf{T}$ & & & & & & & & & & & \\
\hline 1 & $\mathrm{~F}$ & 48 & + & 36 & & 100/ 45/ T10 & 46 & 3 & 4 & 0 & 17 & 2.2 & SS/IS & II & ॥ & 3839 & 0.342 & ACR & 3766 & 0.345 & ॥ & II \\
\hline 2 & $\mathrm{~F}$ & 54 & & 3 & $S$ & $90 / 40 / \mathrm{T} 10$ & \begin{tabular}{|l|l}
6 & 6 \\
\end{tabular} & 3 & 4 & 0 & 19 & 1.6 & SS/IS & I & I & 4221 & 0.457 & ACR & 3860 & 0.593 & I & I \\
\hline 4 & $\mathrm{~F}$ & 63 & + & 60 & & $100 / 60 / \mathrm{T} 10$ & $8 \quad 8$ & 3 & 4 & 0 & 20 & 2.9 & SS/IS & II & II & 4195 & 0.438 & ACR/TLBH & 5578 & 0.496 & II & II \\
\hline 5 & M & 54 & + & 96 & & 100/ 20/ L2 & 44 & 3 & 3 & 0 & 14 & 3.9 & $\mathrm{SS} / \mathrm{IS}$ & 1 & I & 10556 & 0.635 & & 10112 & 0.616 & 1 & 1 \\
\hline 6 & $\mathrm{~F}$ & 55 & + & 108 & & 130/30/ T10 & \begin{tabular}{|l|l}
6 & 6 \\
\end{tabular} & 4 & 4 & 0 & 14 & 2.0 & SS/IS & II & III & 1497 & 0.368 & ACR & 4730 & 0.431 & II & III \\
\hline 7 & $\mathrm{~F}$ & 66 & + & 84 & & 100/ 30/ L2 & 44 & 3 & 3 & 0 & 14 & 4.0 & $\mathrm{SS} / \mathrm{IS}$ & II & I & 1595 & 0.18 & TLBH & 2183 & 0.254 & II & 1 \\
\hline 8 & $\mathrm{~F}$ & 62 & & 120 & & $140 / 50 /$ T8 & 22 & 4 & 2 & 0 & 10 & 3.4 & $S S / I S$ & II & 1 & 5061 & 0.398 & ACR & 3262 & 0.526 & II & 1 \\
\hline
\end{tabular}

Source: Medical records from Irmandade Santa Casa de Misericórdia de São Paulo.

N: Number, M: Male, F: Female, Dom: Dominance, +: Dominant side operated, TS: Time with symptoms, TH: Trauma history, Elev: Elevation, LR : Lateral rotation, MR: Medial rotation, UCLA : University of California at Los Angeles, P: Pain, F: Function, AAF: Active anterior flexion, AAFS: Active anterior flexion strength, S: Satisfaction, T: Total, SI: Size of injury, G: Goutallier, SS: Supraspinatus, IS: Infraspinatus, MOA: Muscle occupation area, PMOA: Proportion of muscle occupation area, ACR: Acromioplasty, TLHB: Tenodesis of the long head of the biceps. 
deltoid muscle belly, so that the pictures of pre and postoperative parameters were similar to the same patient.

After selecting the image, it was saved on file and opened in Adobe Photoshop CS3 ${ }^{\circledR}$ software. With used the quick selection tool, which automatically selects areas of similar brightness. The area in pixels of the supraspinatus muscle belly was initially calculated. (Figure 2) Then, using the same tool, the supraspinatus fossa area in pixels was calculated. (Figure 3) Values of the first area were divided by the second obtaining the muscle ratio in the fossa.

The muscle ratios were calculated for the ten patients, and grouped into two groups (pre- and postoperative). Values of the two groups were compared using the Wilcoxon- $t$ test used for paired and nonparametric variables with small samples. The significance level was set at $5 \%(p<0.05)$. The software SPSS (Statistical Package for Social Sciences) version 19.0 for Windows was used.

In this work, using the selected "y" image of the scapula one differs the notion of fatty infiltration of the supraspinatus, which is the amount of fat in the muscle and muscle atrophy that was estimated by the amount of supraspinatus muscle within its cavity. ${ }^{18}$ This study was approved by the hospital's Ethics Committee with protocol number 106/11 and all selected patients and participants submitted to examination and treatment of rotator cuff injury signed the Free and Informed Consent form.

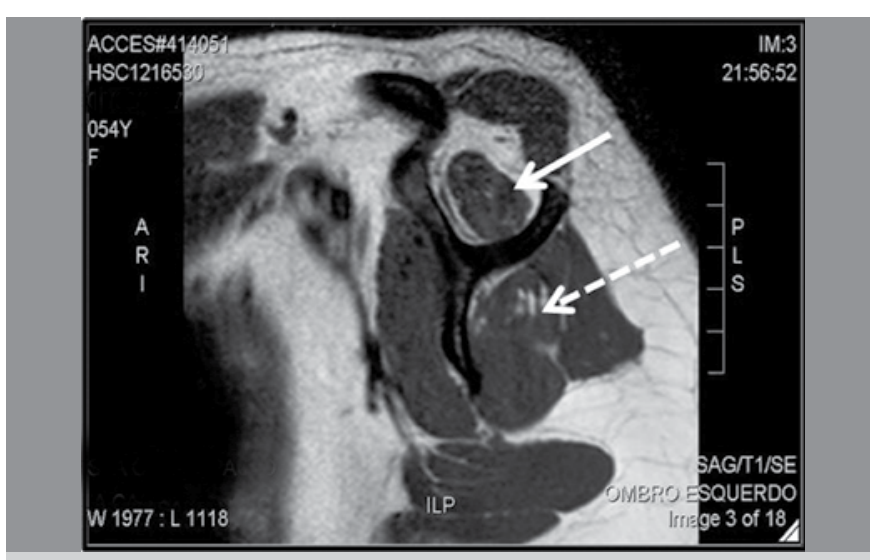

Figure 1. NMR in weighted oblique sagittal sequence in T1. Supraspinatus muscle indicated by the full line arrow and infraspinatus muscle indicated by the dotted arrow.

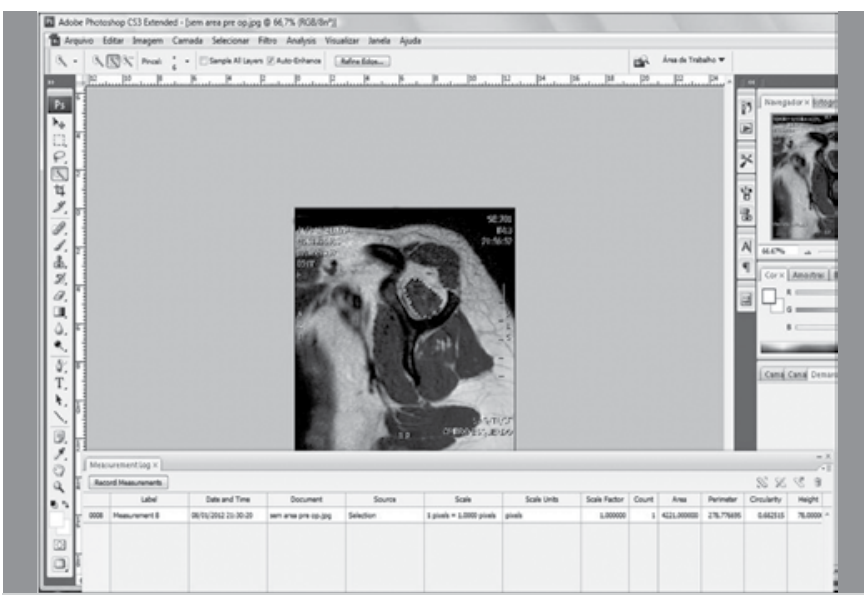

Figure 2. Oblique sagittal NMR cut in T1: it is observed that the spine of scapula is in continuity with the body, forming a "Y" shape.

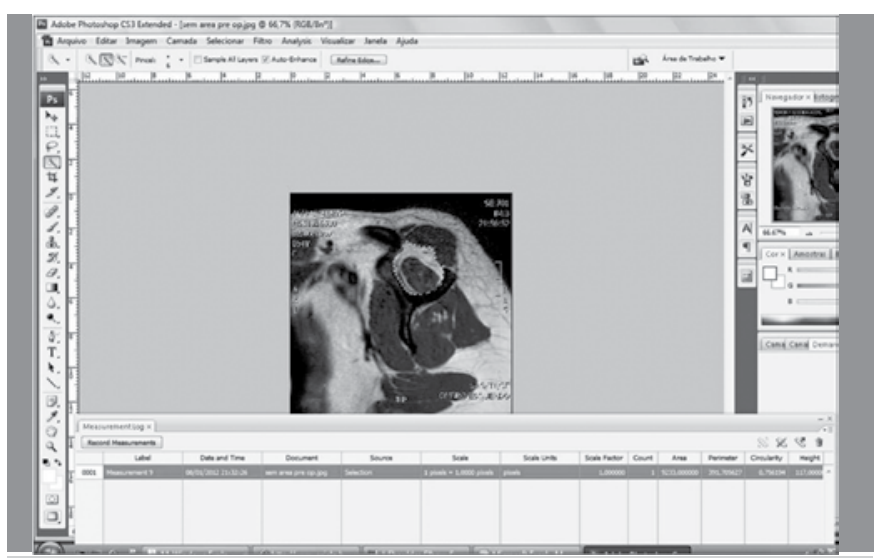

Figure 3. Image of the supraspinatus fossa area.

\section{RESULTS}

The muscle ratios were calculated for all ten patients and grouped into two groups. (Table 2) Group 1 (preoperative) had on average 0.4162 ; ranging from 0.180 to 0.635 . Group 2 (after surgery), had the average value of 0.4862 ; ranging from 0.254 to 0.631 .

It was found that there was a statistically significant increase $(p=0.013)$ between pre and postoperative images, as compared by the Wilcoxon t-test. The increased muscle ratio in group I (preoperative) was 0,416 on average (range 0.18-0.635), whereas group II (post) was on average 0.486 (range, 0.254-0.631). Despite the statistically significant increased muscle proportion of the supraspinatus, the fatty infiltration of both the supraspinatus and infraspinatus, according to the classification of Goutallier et al., ${ }^{6}$ remained unchanged in the pre and postoperative images.

Table 2. Assessment of muscular proportions of the supraspinatus cavity.

\begin{tabular}{c|c|c}
\hline Patients & Group 1 (pre) & Group 2 (post) \\
\hline 1 & 0.342 & 0.354 \\
\hline 2 & 0.457 & 0.593 \\
\hline 3 & 0.624 & 0.631 \\
\hline 4 & 0.438 & 0.496 \\
\hline 5 & 0.635 & 0.616 \\
\hline 6 & 0.368 & 0.431 \\
\hline 7 & 0.18 & 0.254 \\
\hline 8 & 0.398 & 0.526 \\
\hline 9 & 0.384 & 0.539 \\
\hline 10 & 0.336 & 0.422 \\
\hline
\end{tabular}

$\mathrm{p}<0.05$, pre: preoperative; post: postoperative.

\section{DISCUSSION}

Chronic rotator cuff injuries are associated with structural and architectural changes of the muscle-tendon unit, including retraction of the tendon, ${ }^{15}$ muscle fat infiltration, interstitial connective tissue proliferation and muscular atrophy. ${ }^{11}$ Even if a repair is successful, these muscle disorders remain irreversible and are associated with high rate of re-ruptures and poor clinical outcomes. ${ }^{3-5,19,20}$ Therefore, an accurate assessment of the quality of the rotator cuff muscles is very important to evaluate the surgical indication and post operative prognosos. ${ }^{10}$

The loss of muscle substance (atrophy) and increased interfascicular fat and fibrous tissue are explained by a shortening of healthy muscle fibers to approximately $50 \%$ of the length original $^{19,20}$ and reorientation of the fibers within the muscle. ${ }^{21}$ 
In pathology, the term fatty degeneration is the accumulation of triglycerides in the cell parenchyma. ${ }^{22}$ As shown by Gerber et al., ${ }^{20}$ fat accumulates in interfascicular and intrafascicular regions in muscle structure in $\mathrm{RCl}$. Therefore, in this work we adopted the term fatty infiltration to refer to changes in muscle fiber observed in MRI.

Gerber et al., ${ }^{23}$ in an experimental study with 12 sheep, reproduced injuries in the infraspinatus tendon left to retract for four months. Then a transcutaneous device for stretching the muscle-tendon unit ( $1 \mathrm{~mm}$ per day) was set. After 16 weeks the tendons were reattached to the greater tuberosity. The muscular structures were evaluated by MRI and CT images through macroscopic, histological and microscopic sections. As conclusion, the authors observed an increase in muscle mass in cases where stretching was successful.

Tae et al., ${ }^{10}$ in 2011 performed a study with the aim of introducing a new method of assessment of fat infiltration and muscle atrophy. By means of MR and CT images, they calculated muscle occupancy rate of supraspinatus using Photoshop software CS $3^{\circledR}$ and correlate the values found to the size of the injury and the degree of fatty infiltration according to Goutallier et al. ${ }^{6}$ They noticed the existence of highly reliable linear relationship between the studied parameters.

This work was based on the same methodology adopted by Tae et al. ${ }^{10}$ for evaluating quantitatively the supraspinatus muscle and for being reproducible. MR images pre and postoperatively were performed at a minimum interval of one month, in order to verify whether the traction of the retracted muscle to reinsert it would occupy a proportionately larger area in its fossa, and this was observed in this study.

Limitations of this study existed in various aspects. MRI examinations, although were standardized with the image cuts made parallel to the glenoid cavity, in some cases did not result in the desired and image predetermined by Thomazeau et al., ${ }^{8}$ which is the "Y" formed by the scapula and the distal clavicle region. To solve this problem, we tried to cut the same "Y" in the scapula at MRI pre and post operative for the same patient, not necessarily the same " $Y$ " section of the scapula would be identical to another patient.

Muscle occupancy rate of the infraspinatus was not calculated, since this study was based on the method of Tae et al., ${ }^{10}$ which focuses only on the supraspinatus muscle. However, as described by Goutallier et al., ${ }^{4}$ Gladstone et al., ${ }^{19}$ and Melis et al. ${ }^{13}$ the degree of fatty infiltration of the infraspinatus influences functional outcomes after rotator cuff repair. Therefore, analysis of infraspinatus and other muscles of the rotator cuff are necessary.

Functional outcomes of patients postoperatively were not assessed, but in the near future those may be obtained and correlated with the findings of this study.

The fatty infiltration did not change after the repair, which was expected according to the literature. ${ }^{3-5,16,17}$ However, studies, albeit experimental, already exist as pointed out by Gerber et al., ${ }^{23}$ trying to prove otherwise, demonstrating that although after suture of the rotator cuff there would be greater supraspinatus muscle occupancy rate in its fossa, and no change in the degree of fatty infiltration.

\section{CONCLUSION}

Finally, we emphasize the importance of this work in the treatment of $\mathrm{RCl}$ with already installed fatty infiltration and muscle atrophy. The results show through MRI, that the proportion of the supraspinatus muscle in his fossa increases in the immediate postoperative period, probably because of the traction exerted on the tendon at the time of repair. However, the muscular architecture with fatty infiltration proved irreversible.

\section{REFERENCES}

1. Sher JS, Uribe JW, Posada A, Murphy BJ, Zlatkin MB. Abnormal findings on magnetic resonance images of asymptomatic shoulders. J Bone Joint Surg Am. 1995;77(1):10-5.

2. Tingart MJ, Apreleva M, Lehtinen JT, Capell B, Palmer WE, Warner JJ. Magnetic resonance imaging in quantitative analysis of rotator cuff muscle volume. Clin Orthop Relat Res. 2003;(415):104-10.

3. Williams MD, Lädermann A, Melis B, Barthelemy R, Walch G. Fatty bow Surg. 2009;18(4):581-7.

4. Goutallier D, Postel JM, Bernageau J, Lavau L, Voisin MC. Fatty muscle degeneration in cuff ruptures. Pre- and postoperative evaluation by CT scan. Clin Orthop Relat Res. 1994;(304):78-83.

5. Liem D, Lichtenberg S, Magosch P, Habermeyer P. Magnetic resonance imaging of arthroscopic supraspinatus tendon repair. J Bone Joint Surg Am. 2007;89(8):1770-6

6. Goutallier D,Beranageau J, Patte D. L' evaluation par le scanner de latrophicite des muscles de la coiffe des rotateurs ayant une rupturetendineuse. Rev Chir Orthop 1989;75(Suppl 1):126-7.

7. Nakagaki K, Ozaki J, Tomita Y, Tamai S. Function of supraspinatus muscle with torn cuff evaluated by magnetic resonance imaging. Clin Orthop Relat Res. 1995;(318):144-51.

8. Thomazeau H, Rolland Y, Lucas C, Duval JM, Langlais F. Atrophy of the supraspinatus belly. Assessment by MRI in 55 patients with rotator cuff pathology. Acta Orthop Scand. 1996;67(3):264-8.

9. Zanetti M, Gerber C, Hodler J. Quantitative assessment of the muscles of the rotator cuff with magnetic resonance imaging. Invest Radiol. 1998;33(3):163-70.

10. Tae SK, Oh JH, Kim SH, Chung SW, Yang JY, Back YW. Evaluation of fatty degeneration of the supraspinatus muscle using a new measuring tool and its correlation between multidetector computed tomography and magnetic resonance imaging. Am J Sports Med. 2011;39(3):599-606.

11. Fuchs B, Gilbart MK, Hodler J, Gerber C. Clinical and structural results of open repair of an isolated one-tendon tear of the rotator cuff. J Bone Joint Surg Am. 2006;88(2):309-16.

12. Jost B, Zumstein M, Pfirrmann CW, Gerber C. Long-term outcome after structural failure of rotator cuff repairs. J Bone Joint Surg Am. 2006;88(3):472-9.

13. Melis B, Wall B, Walch G. Natural history of infraspinatus fatty infiltration in rotator cuff tears. J Shoulder Elbow Surg. 2010;19(5):757-63.

14. Codsi M, Mccarron J, Brams JJ. The shoulder. Clinical evaluation of shoulder problems. 4th ed. Philadelphia: Saunders Elsevier; 2009.

15. Ellman H, Kay SP. Arthroscopic subacromial decompression for chronic impingement. Two- to five-year results. J Bone Joint Surg Br. 1991;73(3):395-8.

16. Gerber C, Fuchs B, Hodler J. The results of repair of massive tears of the rotator cuff. J Bone Joint Surg Am. 2000;82(4):505-15.

17. Cofield RH. Subscapular muscle transposition for repair of chronic rotator cuff tears. Surg Gynecol Obstet. 1982;154(5):667-72.

18. Mellado JM, Calmet J, Olona M, Esteve C, Camins A, Pérez Del Palomar L, et al. Surgically repaired massive rotator cuff tears: MRI of tendon integrity, muscle fatty degeneration, and muscle atrophy correlated with intraoperative and clinical findings. AJR Am J Roentgenol. 2005;184(5):1456-63.

19. Gladstone JN, Bishop JY, Lo IK, Flatow EL. Fatty infiltration and atrophy of the rotator cuff do not improve after rotator cuff repair and correlate with poor functional outcome. Am J Sports Med. 2007;35(5):719-28.

20. Gerber C, Meyer DC, Schneeberger AG, Hoppeler H, von Rechenberg B. Effect of tendon release and delayed repair on the structure of the muscles of the rotator cuff: an experimental study in sheep. J Bone Joint Surg Am. 2004;86(9):1973-82.

21. Meyer DC, Hoppeler H, von Rechenberg B, Gerber C. A pathomechanical concept explains muscle loss and fatty muscular changes following surgical tendon release. J Orthop Res. 2004;22(5):1004-7.

22. Abbas AK, Fausto N, Kumar V, Michell RN. Lesão celular, morte celular e adaptações. In: Robbins patologia básica. 8a. ed. Rio de Janeiro: Elsevier; 2008. p. 25

23. Gerber C, Meyer DC, Frey E, von Rechenberg B, Hoppeler H, Frigg R, et al. Neer Award 2007: Reversion of structural muscle changes caused by chronic rotator cuff tears using continuous musculotendinous traction. An experimental study in sheep. J Shoulder Elbow Surg. 2009;18(2):163-71. 